ORIGINAL ARTICLE

DOI: $10.34057 /$ PPj.2020.39.03.003

Pelviperineology 2020;39(3):85-89

\title{
Bilateral Sacrospineous Colposupension in the treatment of female genital prolapse: Risk-Benefit Considerations and Six Months Follow-up
}

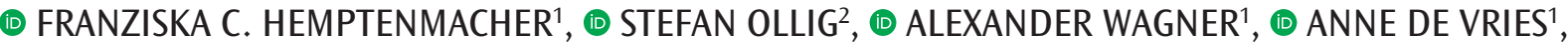 \\ (1) DIRK G. KIEBACK ${ }^{1}$
}

\begin{abstract}
1Department of Obstetrics and Gynaecology, Ev.-Luth. Diakonissenanstalt Knuthstrasse 1, 24939 Flensburg, Germany 2Department of Obstetrics and Gynaecology Diakonissenkrankenhaus Dresden, Holzhofgasse 29, 01099 Dresden, Germany
\end{abstract}

\section{ABSTRACT}

Objective: Central defects in the stability of the pelvic floor present an anatomical problem that afflict women frequently at an advanced age, but also are observed in young women with typical risk factors i.e. obesity and high parity.

Materials and Methods: Based on the encouraging results of the transperineal bilateral sacrospineous colpofixation technique (TPBCF). the vaginal minimally invasive single incision Bilateral Sacrospineous Colposuspension (BSC) using the extremely macroporous lightweight HexaPro polypropylene tape in combination with the i-Stitch instrumentation was developed in order to minimize the amount of foreign body implanted into the patient, facilitate ingrowth of the mesh and for the first time add elasticity and a self-adjusting character to the profile of apical suspension.

Results: In a study of 132 patients with vaginal prolapse surgical and functional outcomes of BSC have been evaluated with 6 months followup. No rectal injury was observed nor was any re-intervention required for any complications. Apical support was reliably achieved. These results were stable when compared with follow-up data at six months postoperatively. No erosion was seen with the exception of a traumatic mesh exposure after vaginal delivery.

Conclusion: The authors conclude, that BSC is an efficient minimally invasive technique for the treatment of female genital prolapse with a very favourable risk/benefit ratio.

Keywords: Bilateral sacrospineous colposuspension; operative therapy; single incision; HexaPro mesh; tape; monofilament; porosity; minimally invasive; vaginal vault prolapse; cervical prolapse; uterine prolapse; surgery; complications; outcome; 6 months results

\section{INTRODUCTION}

Central defects in the stability of the pelvic floor present an anatomical problem afflicting women frequently at an advanced age, but also observed in young women with typical risk factor i.e. obesity and high parity. Recently, encouraging results have been reported after transperineal bilateral sacrospineous colpofixation (TPBCF). ${ }^{1,2}$

Historical treatment options include abdominal surgical interventions such as sacrocolpopexy or fascial slings, ${ }^{3,4}$ and operations via the vaginal approach such as the unilateral

Address for Correspondence: Dirk G. Kieback, Department of Obstetrics and Gynaecology, Ev.-Luth. Diakonissenanstalt Knuthstrasse 1, 24939 Flensburg, Germany E-mail: dirk.kieback@diako.de ORCID ID: orcid.org/0000-0001-8651-9353

Received: 10 February 2020 Accepted: 12 May 2020

${ }^{(C)}$ Copyright 2020 by the International Society for Pelviperineology / Pelviperineology published by Galenos Publishing House. 
Amreich-Richter operation with the vaginal apex sutured to the uterosacral ligament or other lateral structures after hysterectomy. ${ }^{5}$ More recently, extensive reconstructions using prosthetic mesh for the induction of neo-ligaments and neofasciae have been advocated, ${ }^{6}$ sometimes also in the context of primary surgical interventions in the unpretreated patient. ${ }^{7}$

Intravaginal slings (IVS) placed transischiorectally have been proposed by Farnsworth ${ }^{8}$ and Petros ${ }^{9}$ shown to be promising in a small series of cases. However, rectal injury and erosions were identified as major problems of this technique which led to the abandonment of IVS. ${ }^{10}$ A refined approach to TPBCF utilizing a standardized 12-step procedure was developed. ${ }^{1}$ Five-year results have recently been reported. ${ }^{2}$ The Bilateral Sacrospineous Colposuspension (BSC) was thereafter developed as a standardized reproducible procedure. ${ }^{11}$ It further minimizes the amount of foreign body implanted into the patient. The HexaPro polypropylene structure facilitates ingrowth of the mesh and in the BSC application for the first time adds elasticity and a self-adjusting character to the profile of apical suspension.

\section{MATERIALS AND METHODS}

The premanufactured BSC-Kit (A.M.I. Inc.) combines a U-shaped structure designed on the basis of the pelvic anatomy, that is comparable to an angulated tape made of HexaPro monofilament macroporous mesh, with two loading units of the I-Stitch-Instrumentation. At a material weight of $21 \mathrm{~g} / \mathrm{m}^{2}$ the entire implant weighs $0.054 \mathrm{~g}$ compared to a regular postal stamp at $0.085 \mathrm{~g}$. The mesh is isoelastic due to its hexagonal structure: $93 \%$ of the mesh surface consists of pores. The tensile strength is $>16 \mathrm{~N} / \mathrm{cm}$.

In histological sections of a human explant on the occasion of a hysterectomy 3 months after previous uterus-sparing BSC the formation of limited fibrosis around each individual HexaPro fiber without confluence was substantiated (Figure 1).

In a prospective study 132 patients were treated by BSC according to the published standardized single incision technique at Elblandklinikum Riesa in an open single centre design. ${ }^{11}$ Patients with significant anatomical defects in the median pelvic compartment resulting in various stages of vaginal, utero-vaginal or cervical prolapse were included. Primary and secondary cases were admitted to the trial. There was no patient selection and no other treatment modality for the treatment of prolapse was used for the duration of the study. There was no simultaneous tension-free vaginal tape or transobturator tape placement at the time of BSC in patients complaining of stress urinary incontinence (SUI).
Vaginal estriol pre-treatment for at least two weeks was mandatory.

Surgery was performed by two designated surgeons under general or regional anaesthesia following the published method..$^{11}$ Follow-up examinations including pelvic ultrasound were performed upon discharge from the hospital and at 6 months after surgery. The efficacy of the apical suspension was assessed as were surgical complications and quality of life parameters.

Intraoperative variables included feasibility of BSC placement, length of surgery, blood loss, injury to adjacent organs. Postoperative parameters were pain, complications i.e. hematoma formation and/or infection and duration of hospital stay. Also, symptoms of SUI, urge, dyschezia, dyspareunia were assessed.

\section{Statistical Analysis}

All postoperative examinations and determinations were performed by a single gyneacology specialist trained as a pelvic floor surgeon, but not otherwise involved in the trial.

Differences between frequencies were assessed using distribution-free statistics i.e Fisher's exact test for small sample sizes or the Wilcoxon-test for differences of medians.

\section{RESULTS}

The mean age of the 132 participants was 68.1 years (standard deviation: 10.3, Table 1). 93\% ( $n=123)$ were postmenopausal, $7 \%(n=9)$ premenopausal, the median body mass index was 27 [(range: 19-39) with parity at 2.2 (range: 1-7)]. The mean American Society of Anaesthesiology patient classification status was 2 (range: 1-3) (Table 2,3).

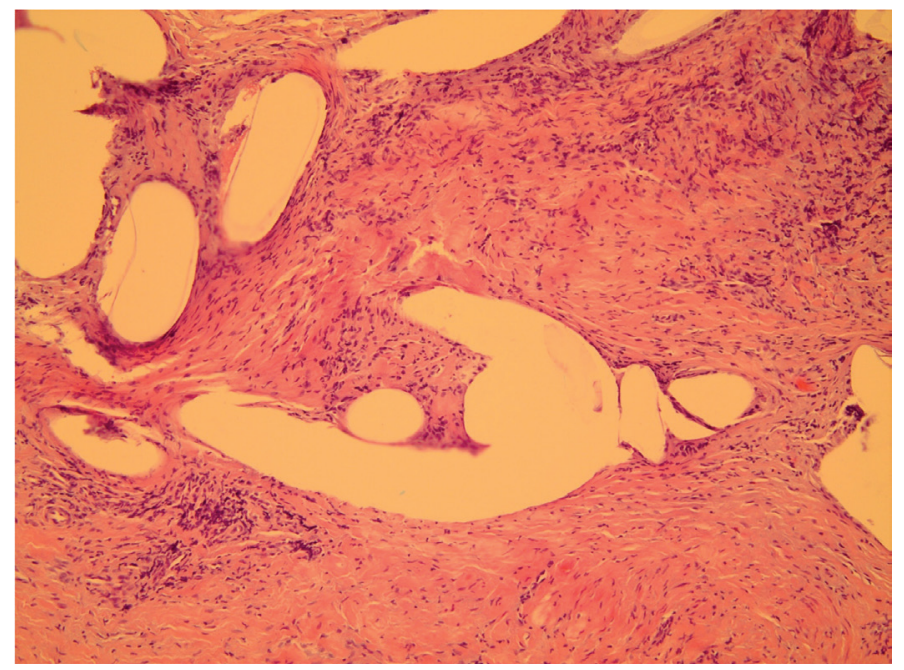

Figure 1. H\&E staining of BSC histology after 3 months (vacuoles represent fibers removed by preparatory process) H\&E: Hematoxylin, BSC: Bilateral Sacrospineous Colposuspension 
Forty-eight patients (36.4\%) had previously undergone hysterectomy (Table 4).

Preoperatively 73 patients (55.3\%) complained of SUI, 76 (57.6) of urge symptoms and $30(22.7 \%)$ of nycturia. Eight patients (6\%) reported dyspareunia preoperatively (Table 5).

BSC was performed preserving the uterus or in combination with hysterectomy (53.8\%). Median operating time was 53 minutes and median blood loss was found to be only $10 \mathrm{~mL}$. Anterior colporrhaphy was performed in 97 patients (73.5\%), posterior colporrhaphy in 46 women (34.8\%). During the course of the hospitalization of 3.3 days (1-6) pain assessed by a visual analogue scale of 1-10 was a median of $2(0-8)$ on the day of surgery, 1.8, 0.8 and 0.4 on the following postoperative days (Table 3). No postoperative infections of the surgical field or hematomas were observed.

There were no failures of apical fixation after six months in the 56 patients (42\%) following the invitation for a follow-up visit.

One patient was pregnant and later delivered spontaneously. After delivery, exposure of the BSC was observed behind a

\begin{tabular}{|c|c|c|c|c|c|c|}
\hline & $\mathbf{n}$ & Mean & SD & Range & Youngest & Oldest \\
\hline Age & 132 & 68.1 & 10.34 & 46 & 43 & 89 \\
\hline
\end{tabular}

\begin{tabular}{|l|l|l|}
\hline \multicolumn{3}{|l|}{ Table 2. Menopausal status } \\
\hline Menopausal status & $\mathbf{n}$ & $\%$ \\
\hline pre-menopausal & 9 & 7 \\
\hline post-menopausal & 123 & 93 \\
\hline n: Number & \multicolumn{2}{|l}{} \\
\hline
\end{tabular}

\begin{tabular}{|l|l|l|}
\hline \multicolumn{3}{|l|}{ Table 3. Patient characteristics } \\
\hline Patient characteristics & 1.61 & $143-175$ \\
\hline Height $(\mathrm{m})$ & 70 & $48-109$ \\
\hline Weight $(\mathrm{kg})$ & 27 & $19-39$ \\
\hline BMI & 2.2 & $1-7$ \\
\hline Parity & 2 & $1-3$ \\
\hline ASA & 2 & \\
\hline $\begin{array}{l}\text { BMI: Body mass index, ASA: American Society of Anaesthesiology patient } \\
\text { classification status }\end{array}$ \\
\hline
\end{tabular}

\begin{tabular}{|l|l|}
\hline Table 4. Surgical Pre-treatment prior to BSC \\
\hline Surgery & $\mathbf{n}$ \\
\hline Hysterectomy & 48 \\
\hline Colpopexy & 4 \\
\hline Anterior repair & 24 \\
\hline Posterior repair & 20 \\
\hline BSC: Bilateral Sacrospineous Colposuspension, n: Number \\
\hline
\end{tabular}

unilateral vaginal tear and $2 \mathrm{~cm}$ of tape were resected at that time. The result of the BSC remained stable. This was the only patient with an "erosion" of the tape, which as such was caused by the obstetrical trauma rather than an adverse tissue reaction. SUI was present preoperatively in 59\% of the patients presenting for follow-up and remained a problem in 21\%. Nycturia had been present in $25 \%$ preoperatively and was reduced to $16 \%$. Dyschezia was reduced from $18 \%$ to $5 \%$.

The frequency of dyspareunia remained numerically unchanged at $6 \%$ with $2 \%$ of patients reporting new onset of dyspareunia while the same number reported being cured of this problem by the surgery (Table 6).

Of the 56 patients presenting for follow-up, 26 (46.4) had preoperative urge problems. Seven of those reported no change in symptoms, four observed de novo symptoms and 19 of those preoperatively afflicted declared having been cured from this problem by the surgery representing $73 \%$ of those present at follow-up with preoperative complaints, the equivalent of a marked reduction in frequency (Table 7).

\begin{tabular}{|l|l|l|l|}
\hline \multicolumn{4}{|l|}{ Table 5. Preoperative symptoms } \\
\hline & $\mathbf{n}$ & $\mathbf{\%}$ & Frequency \\
\hline SUI & 73 & 55.3 & - \\
\hline Urge & 76 & 57.6 & - \\
\hline Nycturia & 30 & 22.7 & $2.6 /$ night (1-8) \\
\hline Dyspareunia & 8 & 6 & - \\
\hline $\begin{array}{l}\text { SUI: Stress urinary incontinence, Urge: Urge urinary incontinence, n: } \\
\text { Number }\end{array}$ \\
\hline
\end{tabular}

Table 6. Comparison of preoperative and postoperative symptoms

\begin{tabular}{|l|l|l|l|}
\hline (n=56) & \% Pre & \% Post & Difference \\
\hline SUI & 59 & 21 & $38 \%$ \\
\hline Nycturia & $25(3 / n)$ & $16(2 / n)$ & $9 \%$ \\
\hline Dyschezia & 18 & 5 & $13 \%$ \\
\hline Dyspareunia & 6 & $6(+2 /-2)$ & - \\
\hline $\begin{array}{l}\text { SUI: Stress urinary incontinence, Pre: Preoperative, Post: Postoperative, } \\
\text { n: Number }\end{array}$ \\
\hline
\end{tabular}

Table 7. Comparison of preoperative and postoperative URGE symptoms

\begin{tabular}{|l|l|l|l|}
\hline \multirow{2}{*}{$(\mathbf{n}=56)$} & Pre, $\mathbf{n}$ & Post, $\mathbf{n}$ & $\begin{array}{l}\text { Relative } \\
\text { difference }\end{array}$ \\
\hline \multirow{2}{*}{ Urge } & \multirow{3}{*}{26} & Unchanged: 7 & - \\
\cline { 3 - 4 } & & De novo: 4 & - \\
\cline { 3 - 4 } & & Cured: 19 & $73 \%$ \\
\hline
\end{tabular}

Urge: Urge urinary incontinence, Pre: Preoperative, Post: Postoperative, n: Number 


\section{DISCUSSION}

Fascia lata slings and suspension procedures using the round ligaments have been abandoned as have resorbable meshes due to the fact, that the body does not maintain neoligaments without continuing stimulation of fibroblasts on site. Sacrocolpopexy with or without prosthetic mesh interposition should be combined with a Burch procedure for optimal results as shown by the studies of the NIH Pelvic Floor Disease Network. ${ }^{12-14}$ In sum, this amounts to a significant surgical intervention with laparoscopic techniques adding their own spectrum of possible complications due to their transabdominal nature.

Amreich-Richter results are known for their surgery-induced dyspareunia, deep pelvic pain and secondary urinary continence problems making them unattractive especially for, but not limited to, the younger patient. ${ }^{15}$ While having been in clinical use for a long time, systematic studies of this entity are few. Modifications using unilateral or bilateral non-resorbable sutures that serve as fixing strings suspending the vaginal apex at a distance from the sacrum, unilateral resorbable suturing and other modifications are based merely on physician preference and have never been formally evaluated and remain experimental with anecdotal results. Therefore, there is no option of a randomized clinical trial comparing new methods against an apical fixation "gold standard".

Large prosthetic implants as a primary treatment approach for female genital prolapse are meeting with increased scepticism due to their potential for complications. The FDA has recently issued a statement to the effect, that large meshes are contraindicated as primary treatment in such situations. ${ }^{16}$ Recently, there are encouraging results using the extremely lightweight high-porosity HexaPro Mesh, a material, that is also employed in the BSC procedure. ${ }^{17,18}$

HexaPro Mesh is one of the most macroporous low-density monofilament meshes available. The use of polypropylene capitalizes on the enormous experience with the biocompatibility of this fiber. The mass of foreign body left in the patient weighs less than a postal stamp and is no larger than that of a suture i.e. during an Amreich-Richter procedure. ${ }^{11}$ It is hard to imagine, that this can be reduced any further without compromising the excellent stability of the result. The isoelasticity of the material is important, because it allows for the in situ self-compensation of any anatomical asymmetry in the placement of the two i-Stich sutures in the pelvis. Their position closely mimics the original anatomy of the uterosacral ligaments recreating the physiological pelvic situation. In the situation after hysterectomy bilateral vagino-sacral support is created.
The principal weakness of the present study lies in the possible selection bias induced by the decline in the number of patients following the invitation for re-examination after 6 months.

Strengths of this trial lie in the still comparably large number of patients and the meticulously standardized surgical procedure. The complete absence of patient selection and the assessment of study endpoints by a non-involved specialist to increase objectivity of the reported outcomes data and their applicability in the routine clinical setting.

Our data show minimal blood loss and an almost complete absence of surgical complications. The risk/benefit ratio of BSC can therefore be considered extremely favourable.

In comparison to other similar approaches of the past such as the IVS and the efficient and well-tolerated TPBCF it still further reduces surgical risks (Table 4) while maintaining excellent stability of the result. ${ }^{2}$ While long-term results have not been made available for BSC so far, it can be expected from the analogy to the anatomical correction with TPBCF, that also in BSC the stability of the apical suspension at six months will translate into similar data at 5 years. ${ }^{2}$

BSC is a standardized, few-step, reproducible and thereby teachable procedure with a steep learning curve. ${ }^{11}$ Designed for a broad clinical application as a single incision minimally invasive vaginal operation under general or spinal anaesthesia it lends itself to the treatment of all age groups from the young premenopausal patient in need of vaginal anatomical correction to women of advanced age. The indication for BSC is vaginal vault, cervical or uterine prolapse including complete procidentia. It is not designed to correct anterior, posterior or lateral pelvic floor defects. While women of child-bearing age should be encouraged to complete family planning before any surgical correction of anatomical pelvic floor problems, it appears, that in the incidental case of a pregnancy after BSC vaginal delivery may be safely considered.

Given the fact, that apical fixation increases the efficacy of anterior colporrhaphy, ${ }^{19}$ it is to be expected, that the combination of these two components will become standard in the near future. Also, in this respect, the compatibility of BSC with additional simultaneous vaginal surgical interventions is an additional advantage of this method.

BSC has the potential to successfully treat SUI as a single intervention or in combination with anterior colporrhaphy. Therefore, any additional procedure addressing the suburethral support should be deferred to the completion of BSC integration and at that point considered after reassessment. 
A result that warrants special attention is the marked decrease in urge complaints after BSC. In view of multi-component complex surgical interventions such as Cesa/Vasa often in combination with suburethral sling operations during secondary operations reporting results around $70-80 \%$ improvement in meeting abstracts, the Australian IVS data and now the BSC data show similar if not better potential for surgically addressing this problem, albeit in a much less invasive fashion with markedly less risk. ${ }^{8,20}$ This property of BSC is currently under more detailed investigation in an international multi-centre trial.

\section{CONCLUSION}

The data of TPBCF were already suggesting refining the concept of generalized statements regarding meshes currently published by the FDA and others. This position is now further substantiated by the data on BSC. The sum of the available data on the isolated apical fixation of the vagina or uterus or uterine cervix by polypropylene mesh indicates, that this approach to pelvic floor repair combining high efficacy and result stability with low operative and postoperative morbidity warrants a consideration separate from larger meshes, especially made out of the older generation of materials.

\section{ETHICS}

Ethics Committee Approval: Routine QM procedure, no specific approval process required.

Informed Consent: It was obtained from the patient.

Peer-review: Externally peer-reviewed.

\section{DISCLOSURES}

Conflict of Interest: Dirk G. Kieback receives royalties and Expert Advisory Fees from the Agency for Medical Innovation (A.M.I.).

Financial Disclosure: The authors declared that this study received no financial support.

\section{REFERENCES}

1. Buerkle B, Ollig S, Kieback DG. Transperineal Bilateral Sacrospineous Colpofixation (TPBCF) for the treatment of vaginal vault prolapse description of a refined method. Pelviperineology 2018; 37: 49-51.

2. Hemptenmacher FC, Ollig S, Süsse A, Kieback DG. Transperineal Bilateral Sacrospineous Colpofixation (TPBCF) for the treatment of vaginal vault prolapse -5 year results. Pelviperineology 2020; 39 : 60-4.

3. Takacs EB, Kreder KJ. Sacrocolpopexy, Surgical Technique, Outcomes, and Complications. Curr Urol Rep 2016; 17: 90.

4. Ijland MM, Fischer D-C, Kieback DG, McGrath G, Farnsworth B. Midline intravaginal slingplasty for treatment of urinary stress incontinence, Results of an independent audit up to 2 years after surgery. Int Urogynecol J Pelvic Floor Dysfunct 2005; 16: 447-54.
5. Lantzsch T, Goepel C, Wolters M, Koelbl H, Methfessel HD. Sacrospinous ligament fixation for vaginal vault prolapse. Arch Gynecol Obstet 2001; 265: 21-5.

6. de Ridder D. Should we use meshes in the management of vaginal prolapse? Curr Opin Urol 2008; 18: 377-82.

7. Dias FGF, Dias PHGF, Prudente A, Riccetto C. New strategies to improve results of mesh surgeries for vaginal prolapses repair--an update. Int Braz J Urol 2015; 41: 623-34.

8. Farnsworth BN. Posterior intravaginal slingplasty (infracoccygeal sacropexy) for severe posthysterectomy vaginal vault prolapse--a preliminary report on efficacy and safety. Int Urogynecol J Pelvic Floor Dysfunct 2002; 13: 4-8

9. Petros PP. Medium-term follow-up of the intravaginal slingplasty operation indicates minimal deterioration of urinary continence with time. Aust N Z J Obstet Gynaecol 1999; 39: 354-6.

10. Feiner B Jelovsek JE, Maher C. Efficacy and safety of transvaginal mesh kits in the treatment of prolapse of the vaginal apex, A systematic review. BJOG 2009; 116: 15-24.

11. Kieback DG. Bilateral Scacrospineous Colposuspension (BSC) for the treatment of vaginal vault prolapse- description of a novel method. Pelviperineology 2019; 38: 46-48.

12. Brubaker L, Cundiff GW, Fine P, et al. Abdominal sacrocolpopexy with Burch colposuspension to reduce urinary stress incontinence. N Engl J Med 2006; 354: 1557-66.

13. Barber MD, Brubaker L, Burgio KL, et al. Comparison of 2 transvaginal surgical approaches and perioperative behavioral therapy for apical vaginal prolapse, The OPTIMAL randomized trial. JAMA 2014; 311: 1023-34.

14. Barber MD, Brubaker L, Nygaard I, et al. Defining success after surgery for pelvic organ prolapse. Obstet Gynecol 2009; 114: 600-9.

15. Kraus P, Krofta L, Krčmář M, et al. Řešení sestupu tří kompartmentů pomocí syntetického implantátu a sakrospinózní fixace, Kohortová prospektivní studie s délkou follow-up pěti let [The results of five years follow-up prospective study of vaginal prolapse repaired by prolift total mesh surgery or sacrospinous fixation]. Ceska Gynekol 2017; 82: 277-86

16. FDA. Urogynecologic Surgical Mesh: Update on the Safety and Effectiveness of Transvaginal Placement for Pelvic Organ Prolapse, 2011. (https://www.fda.gov/downloads/MedicalDevices/Safety/ AlertsandNotices/UCM262760.pdf).

17. Brandt A, Ulrich D, Kuszka A, et al. Treatment of pelvic organ prolapse using a lightweight modified Hexapro mesh. Pelviperineology 2018; 37: 39-41.

18. Brandt A, Kuszka A, Niesel A, et al. 1-year outcome after treatment of uterovaginal prolapse with a 6-point mesh. Neurourol Urodyn 2019; 38: 1129-34.

19. Maher C, Feiner B, Baessler K, Christmann-Schmid C, Haya N, Marjoribanks J. Transvaginal mesh or grafts compared with native tissue repair for vaginal prolapse. Cochrane Database Syst Rev 2016; 2: CD012079.

20. Mauch ED, Deubler K, Kneer G. Cesa/Vasa: neue Operationsverfahren zur Behandlung der Drang- und Mischinkontinenz und des Deszensus Geburtshilfe Frauenheilkd 2014; 74 doi: 10.1055/s-00341388272. 